\title{
Multifunctional Lightweight Aggregate Containing Phase Change Material and Water for Damage Mitigation of Concrete
}

\author{
Wenyu Liao', Aditya Kumar ${ }^{2}$, Kamal Khayat ${ }^{1}$ and Hongyan $\mathrm{Ma}^{1 *}$
}

This paper presents an innovative concept of multifunctional lightweight aggregate, which is produced by loading phase change material (PCM) into the interior of lightweight sand (LWS) and sealing the surface pores using water. The PCM loaded in the LWS functionalizes it as a temperature management agent in concrete, and the water in surface pores enables internal curing. It has been found that the particle shape and pore structure of crushed expanded shale LWS makes it an ideal carrier for PCM, loading sufficient PCM and maintaining better (compared to natural sand) mechanical interlocking. When coupled with the internal curing effect, the LWS yields an interpenetrated interfacial transition zone with the cement paste, leading to a compressive strength comparable to natural sand mortar. The hydration products penetrated into the surface pores also helps stabilizing PCM in the LWS. However, any PCM residuum non-stabilized in LWS tends to compromise the strength. Under an optimized scenario, the LWS-PCM composite aggregate is produced by grading, PCM impregnation, rinsing, and water saturation. A mortar proportioned with this aggregate yields comparable 28-day strength to the reference mortar and a $63 \%$ lower autogenous shrinkage (because of internal curing). Furthermore, it shows a $7{ }^{\circ} \mathrm{C}$ lower semi-adiabatic temperature rise, delayed appearance of peak temperature and gentled cooling curve. These results indicate that the functional aggregate can effectively mitigate the risk of thermal cracking in early-age mass concrete. In addition, PCM remained in aged concrete has a potential to improve its adaptivity to temperature fluctuations in the service environment.

Keywords: Phase change material (PCM); Lightweight sand (LWS); Cement mortar; Strength; Shrinkage; Thermal adaptivity; Multifunctional

Received 28 November 2019, Accepted 10 December 2019

DOI: $10.30919 /$ esmm5f606

\section{Introduction}

Phase change materials (PCMs) have been widely used in the fields of heat energy storage and temperature management, owing to their high energy density and capacity. ${ }^{1-3}$ In recent years, the merits of PCMs have been leveraged in concrete technology, aiming to mitigate deteriorations of concrete due to (internal and external) temperature swings. These thermal damages include, but are not limited to, early-age thermal cracking in mass concrete, ${ }^{4}$ thermal curling and thermal fatigue cracking of concrete pavement, ${ }^{5}$ as well as freeze-thaw cycling induced damage. ${ }^{6}$ However, the PCMs, especially solid-liquid PCMs, can interfere the hydration of cement and strength development of concrete..$^{7.9}$ The mechanisms of the interference could be rooted in retarded cement hydration kinetics, possible reactions with hydration products, formation of defects in bulk paste and weakening effect on the interface between aggregate and bulk paste. To avoid these negative interferences, the solid-liquid PCMs normally need to be loaded in different carriers before mixing with concrete. According to the type and form of carriers, the PCM-carrier composites can be classified to three categories: micro-

${ }^{\prime}$ Department of Civil, Architectural and Environmental Engineering, Missouri University of Science and Technology, Rolla, MO 65401, USA

${ }^{2}$ Department of Materials Science and Engineering, Missouri University of Science and Technology, Rolla, MO 65401, USA

*E-mail:mahon@mst.edu encapsulated PCMs (MPCMs) using in-situ formed microcapsule, ${ }^{10}$ form-stabilized PCMs using porous materials (e.g., lightweight aggregate), ${ }^{11}$ and macro-encapsulated PCMs using relative large sealable container (e.g., hollow steel balls and epoxy wrapped lightweight coarse aggregate). ${ }^{12}$ For more details of different encapsulations readers are referred to a recent review by Milian et al. ${ }^{13}$

In spite of the employment of various carriers, many past studies have come across the same problem that the incorporation of PCMs into concrete would compromise the compressive strength of concrete, ${ }^{14-16}$ resulting from the following reasons: ${ }^{17}$ (1) the PCM melted from the surface or leached out from the interior of porous carrier can poison the hydration process of cement, leading to lower degree of hydration; (2) softer carriers (e.g., microcapsules and lightweight aggregate) which act as defects in the matrix of concrete; and (3) poorer interfacial bond between the carriers and cement paste, which can be attributed to existence of PCMs at the interface (e.g., in the case of porous carriers) or hydrophobic surface of the carriers (e.g., polymeric microcapsules, epoxy wrapping and steel ball). This strength reduction phenomenon is quite severe in even better part of these cases. Reductions of $40 \%$ and $45 \%$ were recorded for a concrete loaded with $20 \mathrm{vol} \%$ MPCMs when it was cured at $20{ }^{\circ} \mathrm{C}$ (below the phase change temperature) and $40{ }^{\circ} \mathrm{C}$ (above the phase change temperature), respectively. ${ }^{16}$ Ramakrishnan et al. ${ }^{19}$ reported $12 \%, 33 \%, 53 \%, 70 \%$ cuts in compressive strength for a mortar with 20, 40, 60 and $80 \mathrm{vol} \%$ sand replaced by the form-stable PCM (PCM loaded expanded perlite particles), respectively. The macroencapsulated PCM, using hollow steel balls as carriers which are equipped by metal clamps for strength enhancement, had 16-42\% 
negative effects on concrete strength when the coarse aggregate replacement percentage increased from 25 to $100 \mathrm{vol} \%{ }^{12}$ It is worth noting that PCMs need to be added in sufficient amount so as to effectively improve the thermal damage resistance of concrete. However, it has been shown that the detrimental effect of PCMs on the compressive strength of concrete increases following increasing rate of incorporation. This conflict leads to a dilemma of balancing the desired amount of PCMs and the required compressive strength of concrete, which is a roadblock urging to be solved for the application of PCMs in concrete technology. Logically, this dilemma can be avoided if PCMs can be added into concrete without compromising the compressive strength.

The raised problem of strength reduction can be mitigated by engineering the cementitious matrix, the interfacial transition zone (ITZ) between matrix and aggregate, and/or the weak aggregate particles. Measures have been taken to improve the mechanical properties of the cementitious matrix in the PCM-incorporated concrete, represented by adding supplementary cementitious materials (SCMs), ${ }^{20}$ nanomaterials, ${ }^{21}$ fibers, ${ }^{22}$ and so on. Nevertheless, these methods can only compensate a part of negative effect on strength from PCM composites. Meanwhile, some studies claimed that choosing PCM inclusions within certain stiffness and volume fraction limits can avoid adverse influence on the fracture resistance of mortars, when these softer inclusions are used to replace stiffer quartz particles. ${ }^{23,}{ }^{24}$ However, it means that such method sets limitations for type and amount of PCM that can be embedded in concrete, which may fail to meet desired cost and performance targets. Lightweight sand (LWS) of crushed expanded shale has been widely studied as a carrier of water for internal curing in ultra-high performance concrete (UHPC), because of its porous nature and relatively high intrinsic strength. ${ }^{25}$ Bentz and Randay ${ }^{26}$ preliminarily explored the feasibility of LWS impregnated with large-volume PCM (LWS-PCM) to enhance the energy storage capacity of concrete, thus manage the temperature rise (more than 1 hour delay and $8{ }^{\circ} \mathrm{C}$ reduction of peak temperature according to the experimental results of semiadiabatic test) in mass concrete for mitigation of the risk of thermal cracking. The authors also claimed that LWS-PCM could greatly alleviate the freezing/thawing damage risk (average 30\% reduction) of a bridge deck, based on simulation results. However, replacing fine aggregate by LWS-PCM in concrete could lead to significant reduction in compressive strength. ${ }^{27}$ Since the LWS can be considered as a strong/tough enough carrier, the observed strength reduced should be attributed to the adverse effects of leached PCM on hydration of cement in the matrix and interfacial bonding in the ITZs. A modified epoxy resin was applied to coat the LWS-PCM so as to mitigate leakage of PCM. However, this still led to a $17 \%$ reduction of compressive strength at $100 \%$ replacement of sand by coated LWS-PCM, comparing to the mortar prepared with LWS. ${ }^{28}$ The epoxy coating could definitely control leakage, however, it also created a soft, yet weak ITZ. ${ }^{29}$

Due to the high intrinsic strength of LWS, we consider it as an ideal carrier for loading PCMs into concrete, given that a sealing strategy can be developed to effectively control PCM leakage without weakening the ITZ. Inspired by the success of internal curing, we propose to use water, and subsequently cement hydration products, to seal the LWS-PCM. It has been proven that when LWS is used for internal curing, hydration products can penetrate into the surface pores of LWS particles, where the local density becomes eventually high due to the restriction from the pore walls. ${ }^{30}$ In the present study, LWS-PCM particles are prepared firstly, and the mechanisms of their negative effect on compressive strength are analyzed; then an effective yet simple method is proposed to eliminate this negative effect. This method requests that the PCM adhered on external surfaces of LWS particles and in near-surface pores is removed, and the near-surface pores are then saturated with water. Such a method proposed against the strengthreduction mechanism is hypothesized to not only prevent leakage of PCMs and functionalize the concrete with a heat energy storage capacity, but also compensate internal moisture loss, and, thus, mitigate shrinkage and enhance ITZs. This hypothesis is eventually tested through measurements of thermal properties, semi-adiabatic temperature rise and shrinkage, as well as characterization of microstructure.

\section{Experiments}

\subsection{Materials}

A portland cement meeting the requirements of ASTM C150 type I cement was used in this study. Its chemical composition was examined by an energy dispersive X-ray fluorescence (XRF) analyzer (X-Supreme 8000, Oxford Instruments, Abingdon, UK). The result is presented in Table 1. Two types of sands shown in Fig. 1, i.e. normal river sand (NS) and lightweight sand (crushed expanded shale, LWS), were used to make mortars. It can be observed that the LWS has a porous structure, much rougher surface texture and more angular shape. The watersaturated LWS has a water desorption value of $96 \%$ under $92 \%$ relative humidity, ${ }^{31}$ that means it can effectively release water to compensate internal moisture loss of mortar due to self-desiccation. The LWS is originally coarser than the NS, according to the gradation curves shown in Fig. 1(c). However, to exclude the effect of aggregate gradation on compressive strength and only focus on the effects of aggregate type

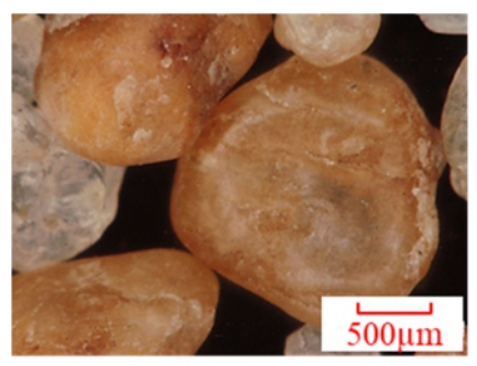

(a)

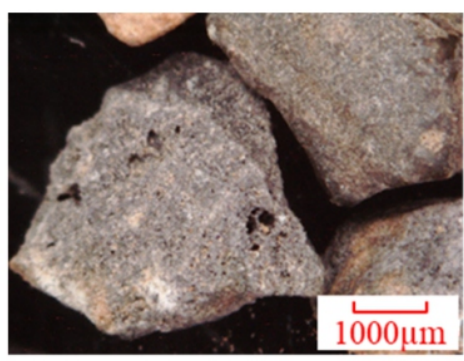

(b)

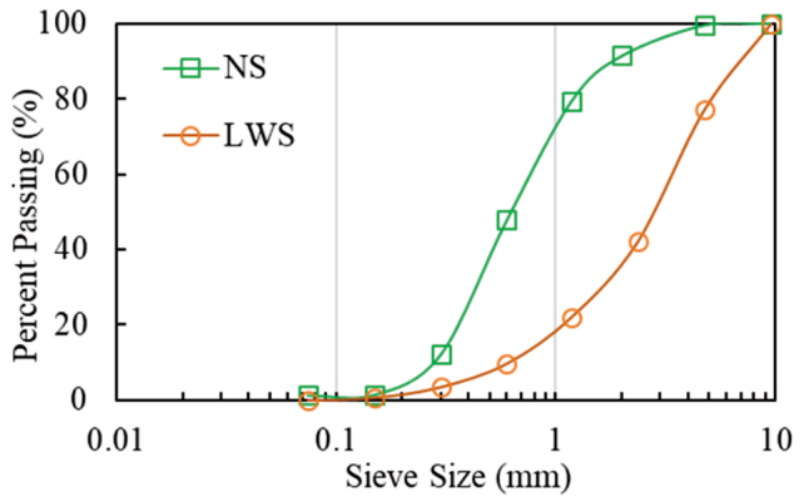

(c)

Fig. 1 Two types of sands: (a) normal river sand (NS); (b) lightweight sand (LWS); (c) gradation curves of received sands. 
(i.e., LWS vs NS), the NS particles in different size ranges were remixed to achieve the same particle size distribution curve as that of LWS. The NS was firstly sieved and separated into different size ranges, then the NS particles in different size ranges were mixed proportionally according to the measured curve of particle size distribution of the LWS. Some physical properties of the natural and lightweight sands are indicated in Table 2. A PCM in the organic paraffin group purchased from Rubitherm $\mathrm{GmbH}$ was used. Its temperature of phase transition is claimed to be $28^{\circ} \mathrm{C}$.

\subsection{Preparation of LWS filled with PCM (LWS-PCM)}

The LWS-PCM was prepared according to the following procedure. Firstly, oven-dried LWS particles were soaked in liquid PCM (when temperature was higher than $28{ }^{\circ} \mathrm{C}$ ) for 72 hours to load the PCM into LWS, then placed on a sieve and oven dried for 48 hours at $38{ }^{\circ} \mathrm{C}$ with mechanical ventilation. In Fig. 2(a), it could be seen that a visible PCM film was covering the surface of the LWS-PCM after oven dry, which will definitely affect the hydration of cement and the bonding between cementitious matrix and aggregate if the LWS-PCM particles are used

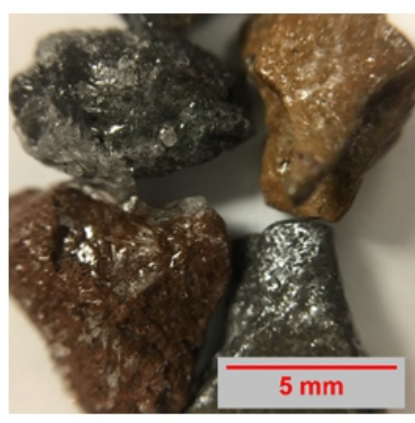

(a)

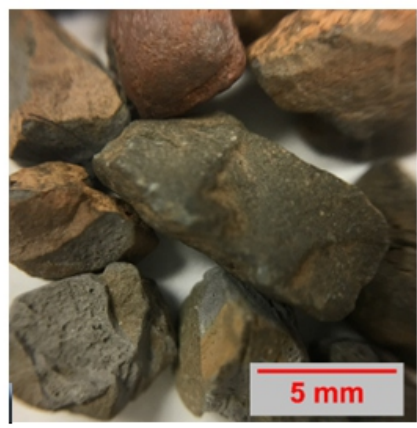

(b)

(a) Immersion in PCM

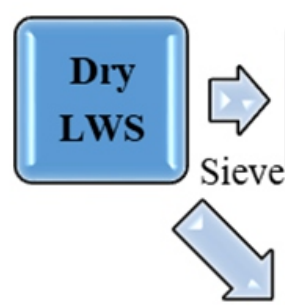

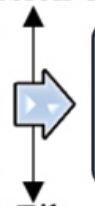

(b) Filter

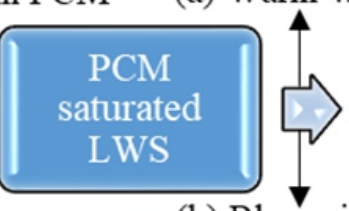

(b) Blow air dry

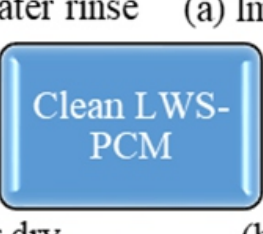

(a) Immersion in water

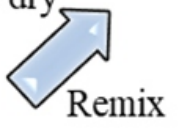

(b) Filter

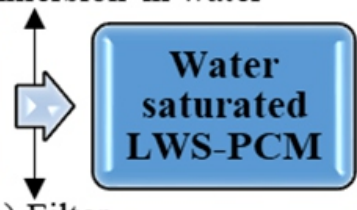

(c)

Fig. 2 Surface of the LWS-PCM (a) before and (b) after removing surface PCM residuum using the warm-water rinse method illustrated in (c) the proposed preparation process.

Table 1 Chemical compositions of cement (oxides, wt $\%$ ).

\begin{tabular}{ccccccccccc}
\hline Component & $\mathrm{CaO}$ & $\mathrm{SiO}_{2}$ & $\mathrm{Al}_{2} \mathrm{O}_{3}$ & $\mathrm{Fe}_{2} \mathrm{O}_{3}$ & $\mathrm{SO}_{3}$ & $\mathrm{MgO}$ & $\mathrm{K}_{2} \mathrm{O}$ & $\mathrm{Na}_{2} \mathrm{O}$ & Minors & LOI \\
\hline $\begin{array}{c}\text { Cement } \\
\text { Type I }\end{array}$ & 65.34 & 18.67 & 4.48 & 3.43 & 2.39 & 2.04 & 0.31 & 0.37 & 0.86 & 1.28 \\
\hline
\end{tabular}

Table 2 Physical properties of sands used in mixtures*.

\begin{tabular}{ccccc}
\hline $\begin{array}{c}\text { Type of } \\
\text { sand }\end{array}$ & $\begin{array}{c}\text { Fineness } \\
\text { modulus }\end{array}$ & $\begin{array}{c}\text { Skeletal density } \\
\left(\mathrm{g} / \mathrm{cm}^{3}\right)\end{array}$ & $\begin{array}{c}\text { Apparent density } \\
\left(\mathrm{g} / \mathrm{cm}^{3}\right)\end{array}$ & $\begin{array}{c}\text { Water absorption } \\
(\%)\end{array}$ \\
\hline NS & 3.46 & 2.61 & 2.61 & 1.2 \\
LWS & 3.46 & 2.29 & 1.60 & 19.7 \\
\hline
\end{tabular}

*The fineness modulus measurements conformed to ASTM C125-19. The skeletal densities, apparent densities, and water absorption were obtained by following ASTM C128-15. During the water absorption test, the saturated-surface-dry (SSD) conditions of both sands were achieved by immersion in water for 72 hours and centrifuge at $2000 \mathrm{rpm}$ for $3 \mathrm{~min}^{32}$ 
to make concrete..$^{7-9}$ Secondly, aiming to remove the PCM film, a warmwater-rinsing method was brought forward after oven drying. The LWSPCM particles were rinsed with warm water (around $40{ }^{\circ} \mathrm{C}$ ); at the beginning, a large amount of oily liquid PCM could be observed on the surface of the drained warm water, and the amount decreased following the rinsing process; the rinsing was not terminated until little oily liquid PCM appeared on the water surface. After rinsing, the surface PCM residuum of the LWS-PCM could be effectively removed for relatively large LWS-PCM particles, as testified in Fig. 2(b). However, it was observed that the surface PCM residuum of relatively small LWS-PCM particles was difficult to be removed. Therefore, to avoid the potential adverse effect on compressive strength, only the portion of LWS particles larger than $1.19 \mathrm{~mm}$ that takes up of $81 \mathrm{wt} \%$ were selected to load the PCM. The LWS were sieved and graded into two groups, i.e. one retaining on \#16 (1.19 mm opening) and the other passing sieve \#16. The LWS grains that were retained on sieve \#16 were used to load the PCM before mixing mortar, while the particles passing sieve \#16 were used without loading PCM. The whole preparation process is summarized in Fig. 2(c).

\subsection{Mix proportion of mortar}

To study the difference brought by each step abovementioned, five groups of mortars were designed as follows:

1) LWS mortar with PCM loaded in all LWS grains without surface rinsing process (Unrinsed LWS-PCM Mortar, UnRLP-M)

2) LWS mortar with PCM loaded in all LWS grains with surface rinsing process (Rinsed LWS-PCM Mortar, R-LP-M)

3) LWS mortar with PCM only loaded in the large-particle portion (retained on sieve \#16) of LWS grains with surfacerinsing process (Graded and Rinsed LWS-PCM Mortar, GrRLP-M)

4) LWS mortar without PCM (LWS-M)
5) NS mortar (NS-M)

When preparing the mortar, we used a water-to-cement $(w / c)$ ratio of 0.4 . The volume of sand accounted for $60 \%$ of total mortar volume. All types of sands were soaked in water for 72 hours before mixing, to achieve a water-saturation status. The mixing procedure of mortars abided by ASTM C305-14. After mixing, the obtained fresh mortars were cast into molds of different dimensions (described in Section 2.5) for various purposes of testing. The specimens were covered with wet burlaps and plastic sheets, demolded at 1 day, wrapped with plastic film, and then cured in a chamber at $23.0 \pm 2.0{ }^{\circ} \mathrm{C}$ until the age of testing. It is worth noting that internal curing is in force for water-loaded (more or less, through LWS) mortars (i.e., R-LP-M, GrR-LP-M and LWS-M).

\subsection{Geometry Evaluation Method of Aggregate}

The shape parameters of NS and LWS aggregates were determined via digital imaging processing (DIP) techniques ${ }^{33}$ as shown in Fig. 3. The DIP method is conducted as follows: (i) imaging, to capture the image of aggregate particles, as shown in Fig. 3(a1) and (b1) for NS and LWS, respectively; (ii) enhancement, to transform the images to black-white binary images in order to clearly differentiate the boundaries of particles, as shown in Fig. 3(a2) and (b2); (iii) segmentation, to label the particles inside an image and detect the edges of particles; and (iv) analysis, to calculate the geometrical properties of the aggregates using the UTHSCSA ImageTool software, according to the principles shown in Fig. 3(c).

In Fig. 3(c), point $\mathrm{O}$ is the centroid as well as the center of gravity of the particle. Aspect ratio (AR) is the ratio between the minimum $\left(r_{\text {min }}\right)$ and the maximum $\left(r_{m a x}\right)$ distance from the particle's boundary to its centroid, ranging from 0 to 1 . Major axis length $\left(d_{\text {major }}\right)$ is the maximum distance between points on the particle's boundary, while minor axis length $\left(d_{\text {minor }}\right)$ is the length of the longest line that can be drawn through the particle perpendicular to the major axis. Elongation (EL) is defined as $d_{\text {maio }} / d_{\text {minor }}$, which is not smaller than 1 . If the ratio is equal to 1 , the

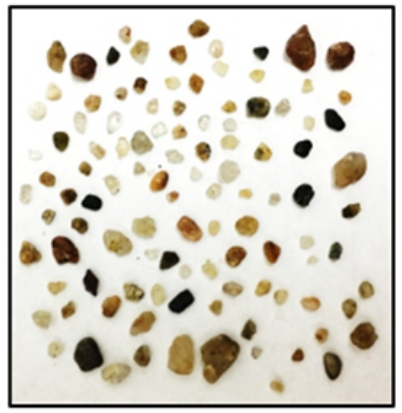

(a1)

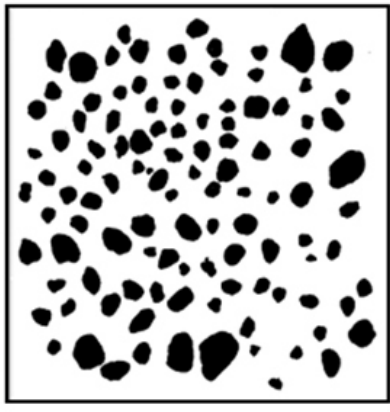

(a2)

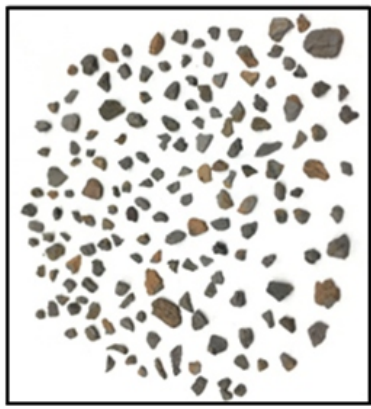

(b1)

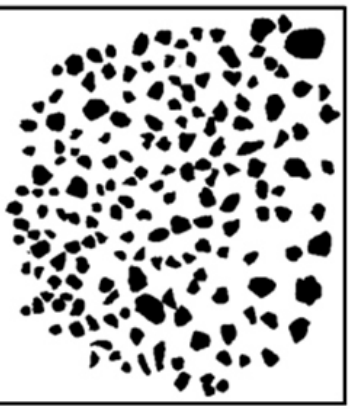

(b2)
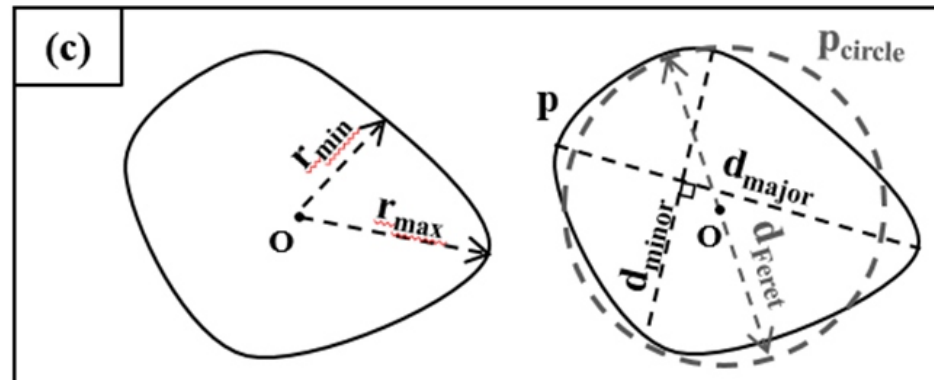

$$
\begin{aligned}
\mathbf{A R} & =\frac{r_{\min }}{r_{\text {max }}}, \mathbf{E L}=\frac{d_{\text {major }}}{d_{\text {minor }}} \\
\mathbf{C O} & =\frac{d_{\text {Feret }}}{d_{\text {major }}}=\frac{\sqrt{4 \pi A}}{d_{\text {major }}} \\
\mathbf{R O} & =\frac{4 \pi A}{p^{2}}
\end{aligned}
$$

Fig. 3 Digital image processing (DIP) of aggregates [a1, b1: digital images of the NS and LWS aggregates, respectively; a2, b2: enhanced binary images of the NS and LWS aggregates, respectively; C: detecting edges of aggregates for calculating shape parameters ${ }^{33}$ of aspect ratio (AR), elongation (EL), compactness $(\mathrm{CO})$, and roundness $(\mathrm{RO})]$. 
object is roughly square or circularly shaped. As the ratio increases from 1 , the object becomes more elongated. Feret diameter $\left(d_{\text {Feret }}\right.$, also named equivalent circular diameter) is the diameter of a circle having the same area as the particle. Compactness (CO) is representing the ratio of the Feret diameter to the major axis length, and ranges between 0 and 1 . Particle with a circularity of 1 are roughly circular. Objects that have complicated, irregular boundaries have smaller compactness. Roundness (RO) measures the ratio of the area of a particle to the area of a circle with the same convex perimeter. Its value lies between 0 and 1 . It equals 1 for a circular object and less than 1 for an object that departs from circularity, except that it is relatively insensitive to irregular boundaries.

\subsection{Testing methods of mortar}

The compressive strength test was carried out according to ASTM C109/109M. Two-inch or [50-mm] cubes of the mortar specimens were used in the compression test at the ages of $1,3,7,14$, and 28 days.

The autogenous shrinkage test complied with the standard of ASTM C1698-09, using a dilatometer with corrugated polyethylene tubes (approximately $400 \mathrm{~mm}$ in length and $30 \mathrm{~mm}$ in diameter). The tubes were cast with fresh mortar and sealed with two end caps, then readings of the length changes of the samples for 28 days at most were taken. The autogenous shrinkages of the mortars (NS-M, LWS-M, or GrR-LP-M) with consistent volume were measured.

Semi-adiabatic calorimetry (Calmetrix F-Cal 8000 semi-adiabatic field calorimeter) was used in this study to quantify the effect of the PCM (loaded in LWS) on the hydration heat accumulation and temperature rise of (large-volume) cementitious materials. The test is compliant with ASTM C1753. Once the mortar was batched, it was cast in a $6 \times 12$ in. cylinder container and then placed in the calorimeter. Each test was performed over a period of approximately 5 days. Semiadiabatic calorimetry tests were performed on 3 different mortar mixtures, i.e. mortars of NS-M, LWS-M, and GrR-LP-M.

A field emission scanning electron microscope (S-4700 FE-SEM, Hitachi, Japan) equipped with energy dispersive spectroscope (EDS) was used to analyze the microstructural morphology and elemental compositions of the samples under back-scattering mode.

A Quantachrome PoreMaster 60 was used for mercury intrusion porosimetry (MIP) test of the LWS. The pore structure parameters as well as pore size distribution curves of the LWS were determined through a data interpretation scheme as recommended by $\mathrm{Ma}^{34,}{ }^{35} \mathrm{~A}$ maximum pressure of 30,000 psi was applied in the MIP test.

\subsection{Testing methods of thermal properties of PCM}

The thermal reliability of the PCM was examined via thermogravimetric analysis (TG), using a SDT Q600 thermal analyzer (TA Instruments) with a heating rate of $10{ }^{\circ} \mathrm{C} / \mathrm{min}$ from 25 to $300{ }^{\circ} \mathrm{C}$ in an argon atmosphere $(100 \mathrm{~mL} / \mathrm{s})$. The thermal energy storage properties of the PCM were tested using a differential scanning calorimeter (DSC Q2000, TA Instrument) over the temperature range of $15-40{ }^{\circ} \mathrm{C}$ at a ramping rate of $5{ }^{\circ} \mathrm{C} / \mathrm{min}$ in a nitrogen atmosphere with flowing rate of $40 \mathrm{~mL} / \mathrm{s}$. The temperature and enthalpy accuracy of the DSC tester were $0.1{ }^{\circ} \mathrm{C}$ and $1 \%$, respectively.

\section{Results and Discussion}

\subsection{Characterization of aggregates}

\subsubsection{Shape characterization of NS and LWS}

Although the same size distribution (gradation) of NS and LWS were used in the mortar mixture design, the shapes of the two types of aggregates can also affect the strength of mortar. In this study, the investigated shape parameters are elongation, aspect ratio, compactness, and roundness, as explained in section 2.

In Fig. 4, all NS and 97\% LWS particles have an elongation lower than 2.0, among which there are two classes of 1.0-1.5 and 1.5-2.0. In the two classes, $80 \%$ NS and $70 \%$ LWS are located in the former class, while $20 \%$ NS and 27\% LWS fall into the latter class. Furthermore, there are 3\% LWS particles possessing an elongation larger than 2.0 and up to 3.5. It can be concluded that LWS appears to be more elongated than NS. In Fig. 5, the shape parameters of elongation, compactness, aspect ratio and roundness of the aggregates are averaged and

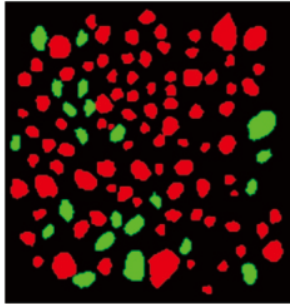

NS

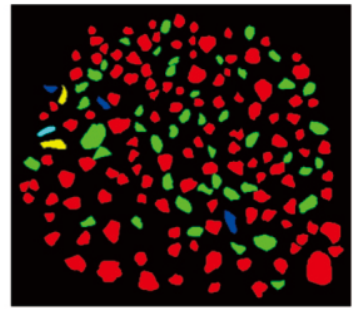

LWS

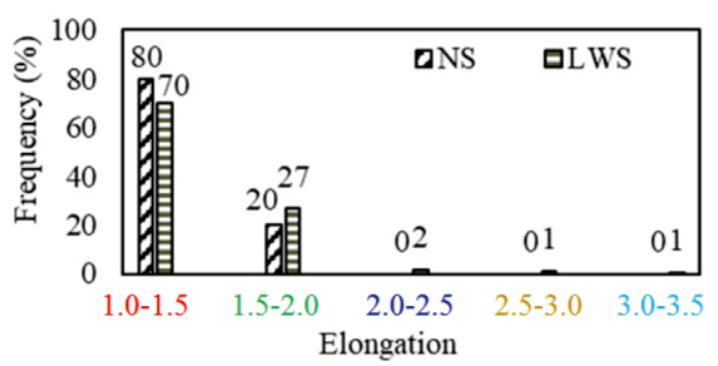

Fig. 4 Elongations of NS and LWS (the particle colors in the images are corresponding to colors of $\mathrm{x}$-values in the bar chart).

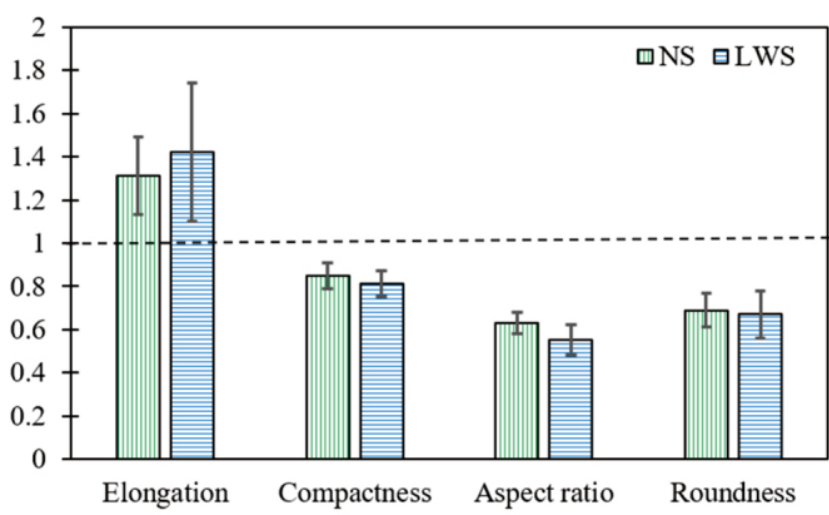

Fig. 5 Shape parameters of NS and LWS, i.e. elongation, compactness, aspect ratio, roundness. 
compared. LWS, with an average elongation value of 1.42 , is $8.4 \%$ more elongated than NS. The lower aspect ratio of the LWS proves its more elongated shape as well. It has been reported that the increase in elongated and flat particles aggravates the stiffness degradation of aggregates, ${ }^{36}$ which is detrimental to the compressive strength of concrete. Moreover, the particles with more complicated and irregular boundaries rather than smooth boundary have a smaller compactness and roundness values. ${ }^{37}$ Fig. 5 indicates that the LWS particles have smaller average values of compactness and roundness, thus more complicated/irregualr boundaries than the NS particle. These morphological characteristics of LWS are positive in establishing the mechanical interlocking between cement paste and aggregate, and, thus, in developing a better strength of mortar/concrete.

\subsubsection{Pore structure and PCM/water absorption of LWS}

As shown in Fig. 1(b), the LWS particles have open pores on the surface, which allows the access of liquid PCM/water. After impregnating the LWS particles with PCM, no encapsulation action was taken because the melted PCM can be held by the capillary force. For a given liquid, the capillary force of a pore is mainly determined by the pore size and liquid properties, which can be calculated using the Young-Laplace equation below.

$$
\begin{aligned}
& p_{\text {cap }}=\frac{2 \gamma \cos \theta}{r} \\
& F_{\text {capilay }}=p_{\text {cap }} \cdot S
\end{aligned}
$$

where $p_{\text {cap }}$ is the capillary pressure, $\gamma$ is the surface tension of liquid, $\theta$ is the contact angle between the liquid and solid, $r$ is the pore radius, $S$ is the surface area of the pore, and $F_{\text {capilay }}$ is the capillary force. For a given liquid, the smaller the pore is, the higher the capillary force is. Although capillary action principles have been well understood, their applications to practical problems of absorption capacity are often limited by complicated pore geometries of porous solids. ${ }^{38,}{ }^{39}$ Hence, the pore structure of the porous LWS is characterized herein to analyze the stability of PCMs in the porous medium in the light of the capillary action theory. In this section, not only pores inside the LWS particles but also pores on the surface are studied.

The sizes of the surface pores determine the degree of difficulty for PCM and water to enter or leak out from the LWS particles. For smaller surface pores, a PCM that is wettable to the LWS surface can be loaded easier due to more significant capillary action, while it is more difficult to leak out too. In Fig. 6(a), different surfaces (i.e., yellowish and grey) of the LWS particles are found, which should be resulted from the calcination (yellowish surface) and crushing (exposed grey surface) processes during production of the LWS. Based on a comparison shown in Fig. 6(b-f), the yellowish surfaces have less and smaller pores, whereas the grey surfaces apparently have more and larger pores. The surface pore sizes of ten random $1.54 \times 1.16 \mathrm{~mm}^{2}$ area on different particles are obtained by DIP method and their distribution is presented in Fig. $6(\mathrm{~g})$. The surface pores have a broad size range, among which most of them are below $60 \mu \mathrm{m}$. It should be noted that pores smaller than $10 \mu \mathrm{m}$ cannot be recognized very well due to the limitation of spatial resolution of the microscope, so the counting of pores smaller than this limit has a non-predictable error.

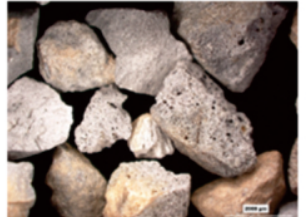

(a) $\times 20$

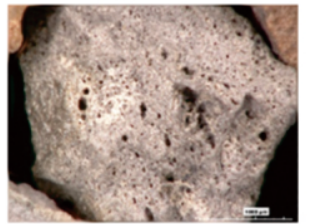

(d) $\times 50$

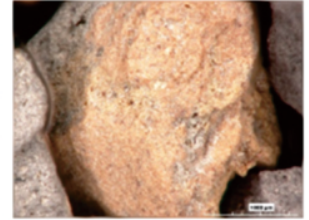

(b) $\times 50$

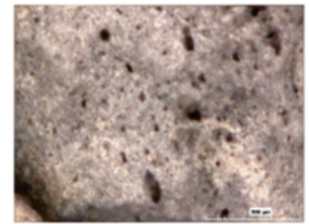

(e) $\times 150$

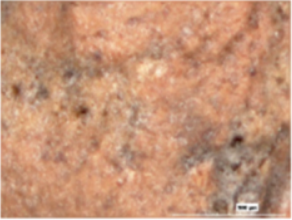

(c) $\times 150$

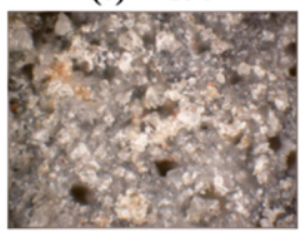

(f) $\times 300$

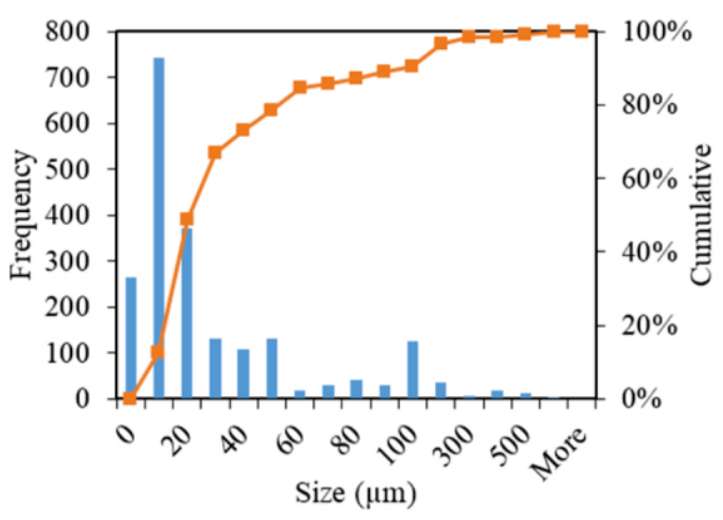

(g)

Fig. 6 Surface pores of LWS particle: (a-f) Pores on LWS surface at different magnifications; (g) Surface pore size distribution obtained by the DIP method.

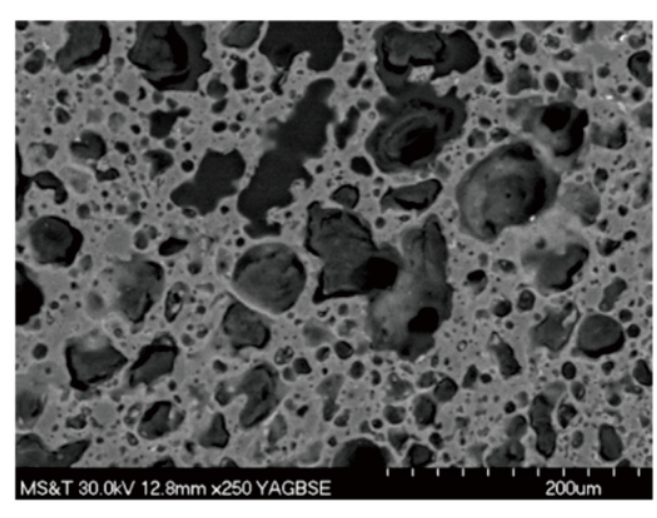

(a)

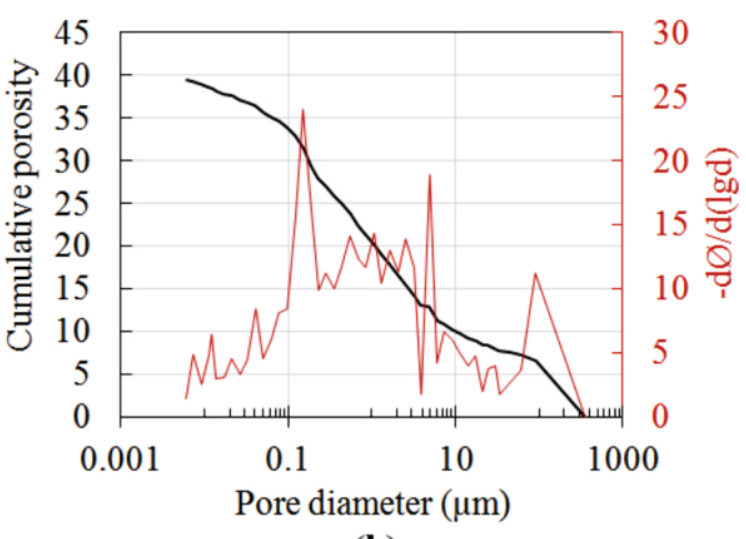

(b)

Fig. 7 Pores inside the LWS: (a) Pore structures; (b) Pore size distribution acquired by MIP. 
Internal pore geometry and pore wall roughness play important roles in the efficiency of fluid flow and the adsorption of liquid inside the porous medium. ${ }^{40}$ In Fig. 7(a), the pore structures and some internal wall surfaces of the LWS are revealed using back-scattered electron imaging. It can be seen that the pore walls are relatively smooth; nevertheless, pores inside the LWS are mostly with irregular shapes. Based on the analysis of twenty-two random images via DIP method, the porosity is larger than $50 \%$. As shown in Fig. 7(b), the porosity of the LWS was determined to be $39.5 \%$ by MIP test, including relatively high fractions of pores with sizes of $100 \mathrm{~nm}-6 \mu \mathrm{m}$ and $30 \mu \mathrm{m}-100$ $\mu \mathrm{m}$. This result is consistent with the measured water absorption of 19.7 wt $\%$ (or $31.2 \mathrm{vol} \%$ ) in Table 2 . The difference of porosities determined by DIP and MIP measurements could indicate a portion of closed pores inside the LWS that are not accessible to liquids (i.e., water and melted PCM).

The intrinsic pore structure of LWS allows it to work as a PCM carrier. As indicated in section 2.3, three types of LWS-PCM using different PCM loading techniques were prepared in this study, i.e. UnRLP, R-LP, and GrR-LP. The PCM absorption capacities of LWS in these three cases are compared in Fig. 8. With the same LWS, the PCM absorption rate decreases because of the rinse-processing of the LWSPCM. Without surface processing, the UnR-LP has an absorption as high as $23.6 \mathrm{wt} \%$ (or $42.4 \mathrm{vol} \%$ ); the rinsing-process can remove 7.4 $\mathrm{wt} \%$ (or 13.3 vol\%) PCM from the surface of LWS-PCM particles (see R-LP vs UnR-LP in Fig. 8); and the exclusion of the small LWS particles for PCM absorption leads to a further reduction of $7.5 \mathrm{wt} \%$ (or $13.5 \mathrm{vol} \%$ ). It substantiates the claim that there is a large amount of PCM surface residuum without taking measure on surface processing (i.e., rinsing). It is worth nothing that the removal of the surface PCM residuum is necessary to avoid compressive strength reduction, as will be shown in section 3.2; and fortunately, the GrR-LP can carry sufficient amount of PCM to functionalize mortar/concrete in some applications, as will be illustrated in section 3.4.

Before mixing with cement, the LWS-PCM particles were saturated with water. The PCM and water absorption ratios of the GrRLP are measured, and the results are listed in Table 3. It can be seen that smaller particles can carry more PCMs after rinsing, and the surface pores can absorb more water too. In Fig. 9, a schematic diagram of a water-saturated GrR-LP particle is presented, in order to illustrate its structure before being put into the mortar. The schematic diagram shows

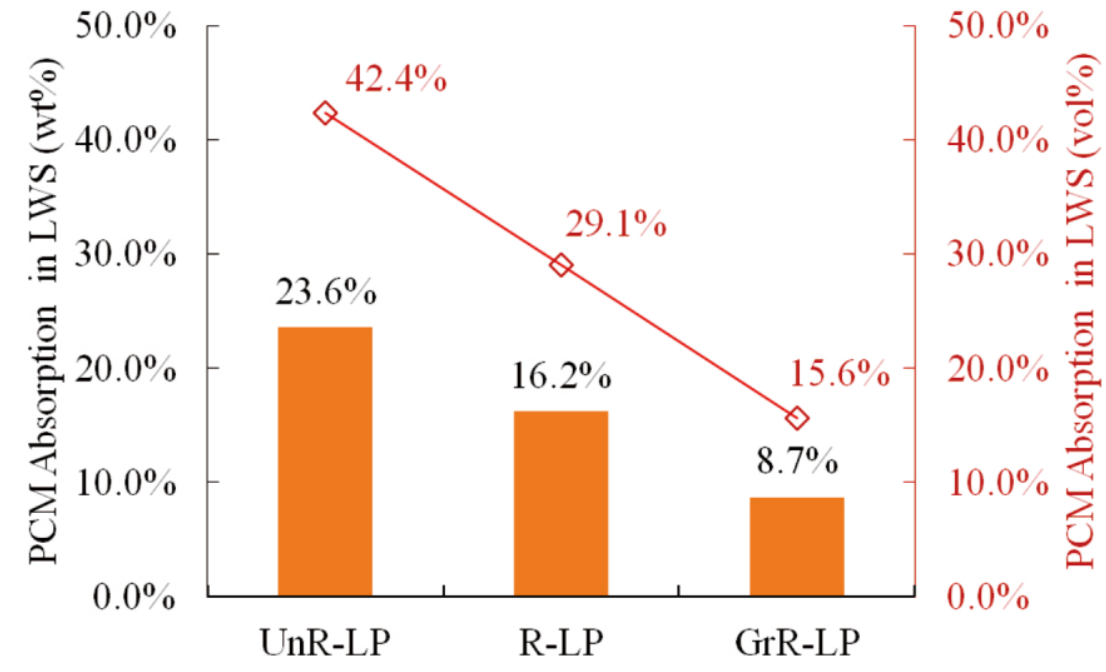

Fig. 8 PCM absorption ratios in three types of LWS-PCM aggregates (wt $\%$ and vol $\%$ are respect to dry LWS).

Table 3 Absorption of PCM and water in the saturated Graded LWS-PCM (GrR-LP) and their densities.

\begin{tabular}{|c|c|c|c|c|c|}
\hline \multirow{2}{*}{ Gradation } & Sieve No. retaining & \#4 & \#8 & $\# 16$ & pan \\
\hline & Sieve opening & $4.76 \mathrm{~mm}$ & $2.38 \mathrm{~mm}$ & $1.19 \mathrm{~mm}$ & $<1.19 \mathrm{~mm}$ \\
\hline \multirow{4}{*}{ GrR-LP } & PCM absorption to dry & & & & \\
\hline & & $10.3 \%$ & $15.2 \%$ & $15.7 \%$ & - \\
\hline & LWS ( wt\%) & & & & \\
\hline & Apparent density $\left(\mathrm{kg} / \mathrm{m}^{3}\right)$ & 1631.6 & 1702.7 & 1789.3 & - \\
\hline \multirow{4}{*}{ SSD GrR-LP } & Water absorption to & & & & $24.3 \%$ \\
\hline & & $3.4 \%$ & $4.0 \%$ & $6.0 \%$ & \\
\hline & LWS-PCM ( wt\%) & & & & (to dry LWS) \\
\hline & Apparent density $\left(\mathrm{kg} / \mathrm{m}^{3}\right)$ & 1668.9 & 1751.2 & 1818.2 & $\begin{array}{c}1967.6^{*} \\
\text { (SSD LWS) }\end{array}$ \\
\hline
\end{tabular}

* saturated with water without absorbing PCM. 
that PCM is imbibed into the inner pores, while water is mostly in the surface layer of the particle. Moreover, a portion of pores (represented by the difference between porosities determined by DIP and MIP) may not be accessible to water and PCM, and they keep empty (see the black colored pores in Fig. 9).

\subsection{Compressive strength and microstructure}

Compressive strength tests and microstructural characterizations were carried out to test our hypothesis that the proposed method (represented by GrR-LP) can load PCM into LWA and mortar/concrete without reducing the compressive strength. The mechanism of strength reduction induced by improper PCM incorporation was also revealed based on microstructural analysis. In Fig. 10, the test results of compressive strengths of the mortars with NS, LWS, and LWS-PCM aggregates prepared with three different processes are exhibited.

According to Fig. 10, the natural sand mortar NS-M appears to have the highest compressive strength. The mortar prepared by water saturated LWS (i.e., LWS-M) can achieve comparable compressive strength to NS-M at 28 days, perhaps due to the internal curing effect and enhanced interfacial interlocking (see section 3.1.1), in spite of weaker aggregate. the compressive strengths of the five mortars at 28 days have an order of UnR-LP-M $<$ R-LP-M $<$ GrR-LP-M $\approx$ LWS-M $\approx$ NS-M. It can thus be concluded that the GrR-LP-M can achieve almost the same 28-day strength as LWS-M and NS-M, which means that the proposed PCM loading method (i.e., loaded in only large particles of LWS plus surface rinsing) can effectively incorporate PCM into mortar/concrete without compromising the compressive strength. As compared to GrR-LP-M (64.5 MPa), the 28-day compressive strengths of the other two LWS-PCM mortars, R-LP-M (50 MPa) and UnR-LP-M (27.1 MPa), are $22.5 \%$ and $58 \%$ lower. Furthermore, the later-age strength development of R-LP-M and UnR-LP-M seems to be limited. The strength reduction can be obviously correlated to the surface PCM residuum on LWS particles: UnR-LP aggregate was not subjected to surface-rinsing, thus has the largest amount of surface PCM residuum (see Fig. 2), corresponding to the largest strength reduction; the surface-rinsing could not effectively remove the surface PCM from small particles, thus, R-LP-M showed moderate strength reduction. In GrR-LP, since surface PCM in large LWS particles can be effectively rinsed off (see Fig. 2) and PCM is not loaded to small particles, the potential negative effects of PCM on cement hydration and interfacial bonding are both eliminated, leading to no strength reduction.

To verify these mechanisms deduced from compressive strength test, we carried out microstructural characterizations on different mortars using back-scattered electon imaging. Fig. 11 contrasts the ITZs in 28day old NS-M and GrR-LP-M. First of all, the LWS particle has a rougher surface and more irragular shape. This is consistent with section

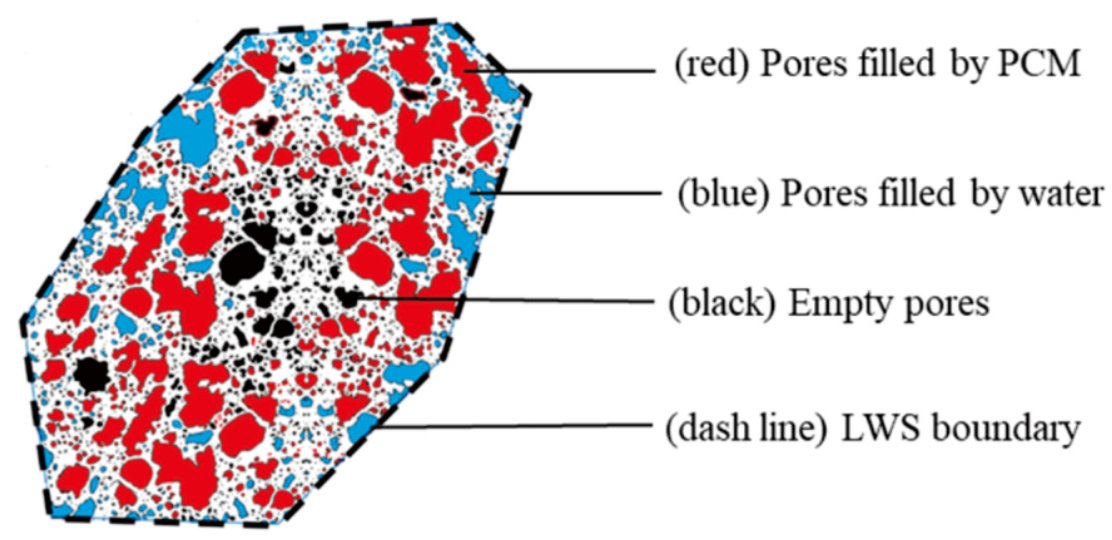

Fig. 9. Schematic diagram of multifunctional aggregate of water-saturated GrR-LP.

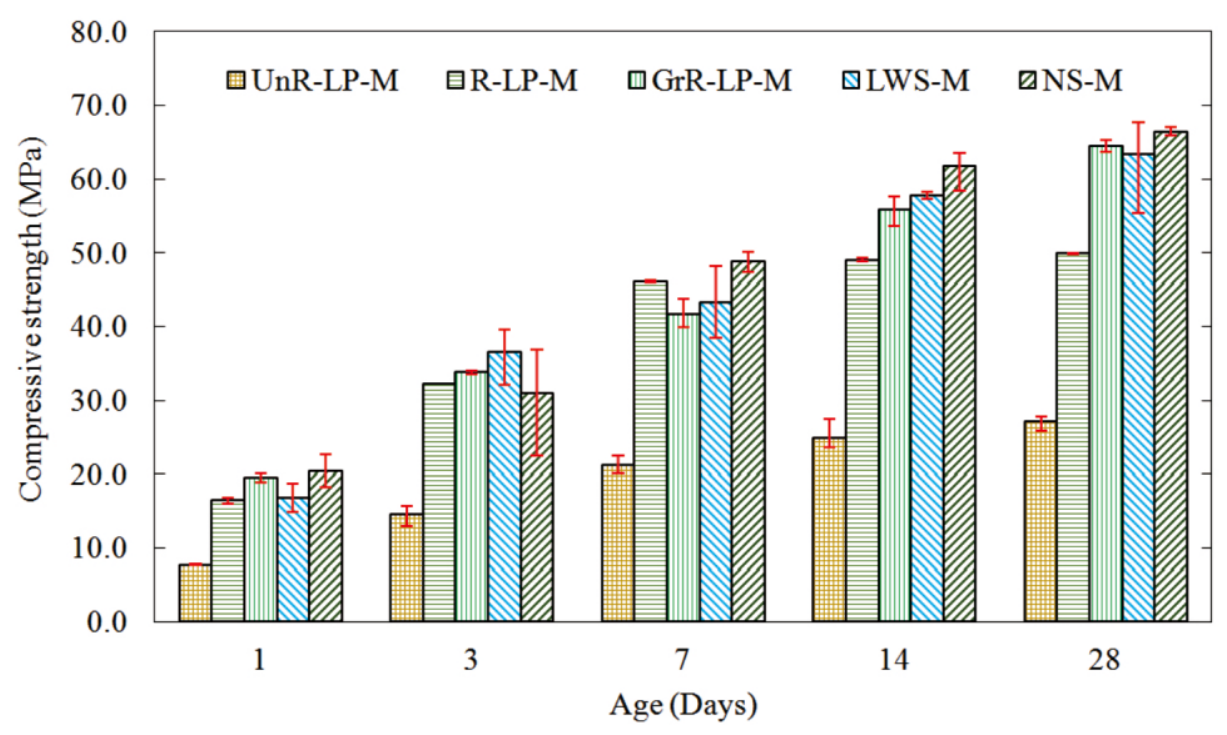

Fig. 10. Development of compressive strength of the five types of mortars. 


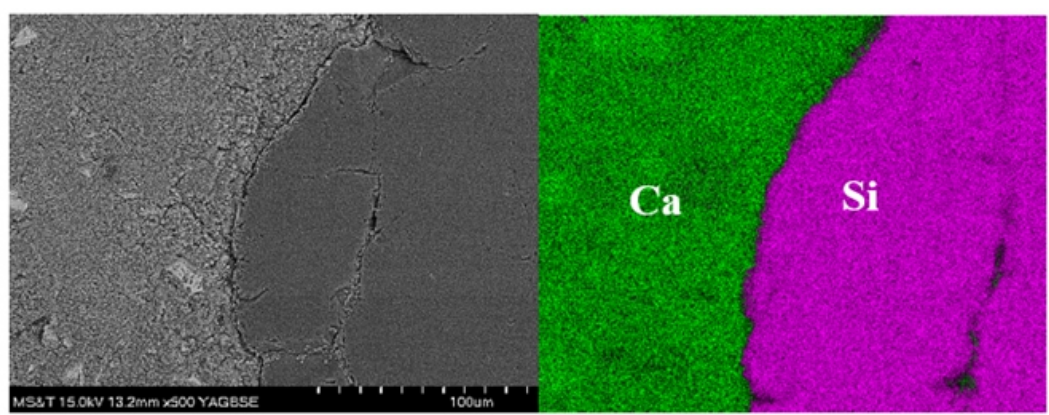

(a)

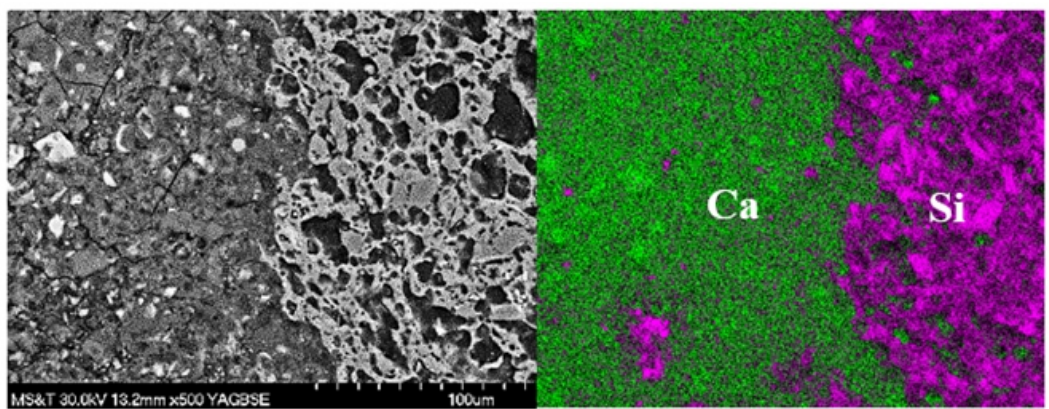

(b)

Fig. 11 Comparison of ITZs in NS-M and GrR-LP-M: (a) cement paste-NS ITZ; and (b) cement paste-LWS ITZ.

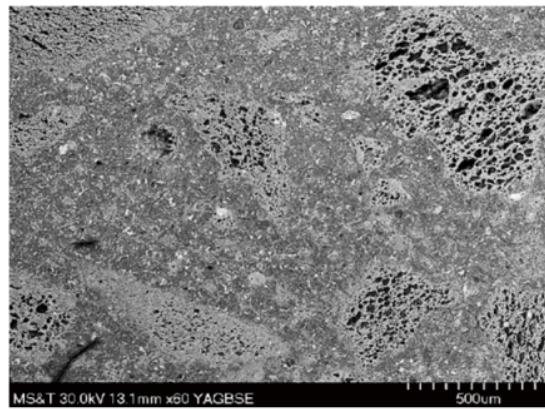

(a)

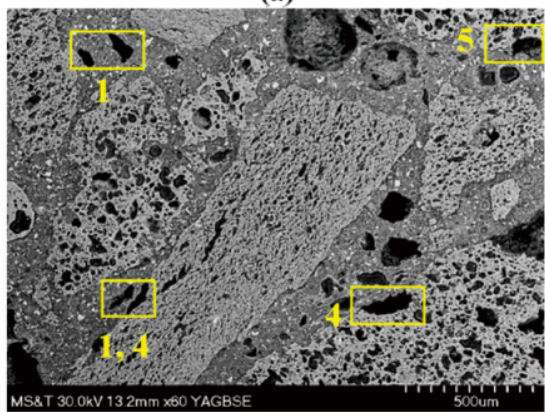

(c)

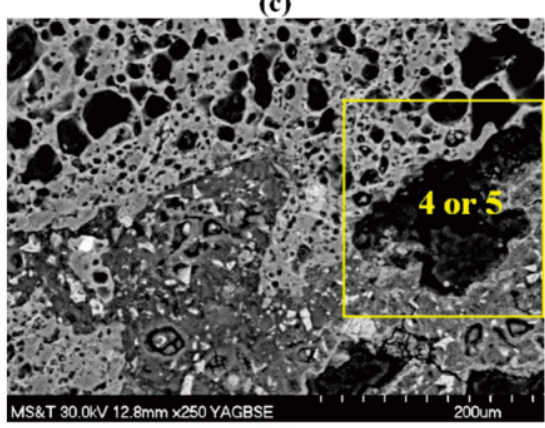

(e)

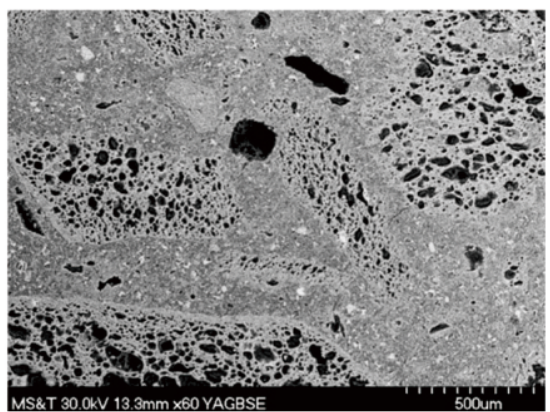

(b)

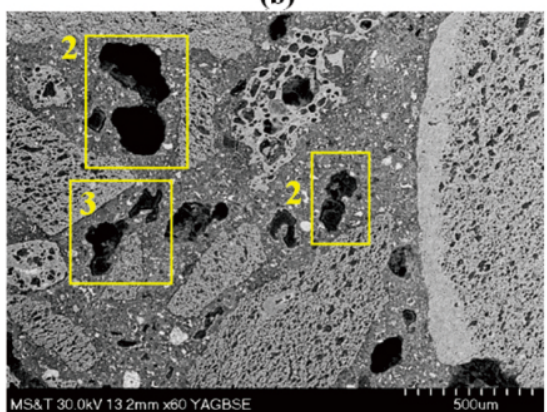

(d)

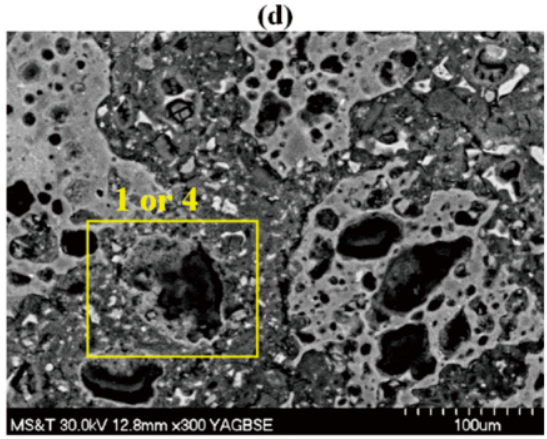

(f)

Fig. 12 Microstructure of LWS-PCM incorporated mortars: (a) GrR-LP-M; (b) R-LP-M; (c-f) UnR-LP-M. (The numbers indicate the types of PCM residua responsible for the formation of the defects) 
3.1.1, resulting in better mechanical interlocking between cement paste and aggregate particles. Furthermore, Fig. 11(a) shows that the ITZ in NS-M appears to be a "gap", while the internal curing effect (because of slow releasing of water absorbed in pores of the surface layer) of LWS could enhance the ITZ and even eliminate the gap-like ITZ, as shown in Fig. 11(b). In addition, the cement paste penetrates into the surface pores of the LWS following the hydration process, as visualized by the diffusion of the green-colored Ca-traced cement phase into the $\mathrm{Si}$ dominated porous LWS phase in Fig. 11(b). This phase diffusion creates an interpenetrated interface, which represents a much stronger interfacial bonding than the ITZ in NS-M.

A series of back-scattered electron images of the microstructures of LWS-PCM mortars, GrR-LP-M, R-LP-M and UnR-LP-M, are collected in Fig. 12. Fig. 12(a) demonstrates a monolithic paste containing LWS particles and interpenetrated interfaces, which endorses the high strength of GrR-LP-M. Fig. 12(b) presents some defects in the cement paste matrix of R-LP-M, which may be due to PCMs trapped on surface of or among small LWS particles. According to Fig. 12(c)(f), a lot of defects are introduced into the matrix of UnR-LP-M, because of the use of un-rinsed LWS-PCM aggregate and PCM residua. In the light of the observations during preparation of the mortars, five types of PCM residua can be identified, as shown by the yellow rectangles and numbers in Fig. 12: (1) bulk PCM particles formed during cooling of PCM that is not absorbed by LWS particles; (2) PCM trapped among small LWS particles (the PCM thus bonds the LWS particles together after cooling); (3) small-volume PCM on the surface of small LWS particles, which can hardly be removed even by rinsing; (4) large-volume PCM on the surface of large LWS particles, which can be removed effectively by rinsing; and (5) PCM leaked out from LWS particles during mixing and vibration of mortar. These formats of PCM are undesired in mortar/concrete, since they are not stabilized in LWS particles. They create defects and weaken the interfacial bonding between cement paste matrix and the LWS particles, which lead to reduced compressive strength. Furthermore, some of the PCM may be further broke up, by either mechanical stirring during mixing or thermal impacts, into small particles that could not be seen in Fig. 12. These small particles may interrupt cement hydration, resulting in limited strength development in later ages, as shown in Fig. 10. As compared to UnR-LP-M, only types (2), (3) and (5) PCM residua may appear in R-
LP-M. That is why much less defects can be seen in Fig. 12(b), and the compressive strength of mortar was only moderately reduced by R-LP aggregates.

\subsection{Autogenous shrinkage}

We claimed that using water (and subsequently hydration products, as shown in Fig. 11) to seal pores in the surface layer of LWS can functionalize the LWS as not only a temperature managing agent (because of the loading of PCM), but also an internal curing agent. To verify this claim, we tested the autogenous shrinkages of three types of mortars - NS-M, LWS-M, and GrR-LP-M. The results are shown in Fig. 13.

According to Fig. 13, the autogenous shrinkage of the NS-M increases gradually and stabilizes after 28 days at nearly $200 \mu \varepsilon$. If water is introduced into mortar/concrete by LWS or other carrier (e.g., superabsorbent polymer), it can compensate the self-desiccation in the microenvironment, and, thus mitigate and even remove the autogenous shrinkage. ${ }^{41.44}$ Compared to NS-M, the LWS-M exhibits an autogenous swelling (up to $100 \mu \varepsilon$ ) within the first 2 days, which may result from osmotic pressure due to internally introduced water and/or enhanced formation of ettringite. ${ }^{45}$, 46 This swelling declines later and reaches a constant of about $38 \mu \varepsilon$ after 14 days. As for the GrR-LP-M, no swelling can be observed, because of much less water introduced through the LWS (only surface pores are saturated with water, as illustrated in Fig. 9). However, the GrR-LP-M does have a significantly smaller autogenous shrinkage than NS-M. The shrinkage stabilizes at 75 $\mu \varepsilon$ after 28 days ( $63 \%$ lower than NS-M). This result proves that LWS partially (only in surface pores) saturated with water can significantly mitigate autogenous shrinkage of mortar/concrete, although the water content is insufficient to completely compensate self-desiccation.

\subsection{Thermal performance and hydration heat regulation}

Along with the incorporation of high-enthalpy PCM, the mortar is expected to gain an improved heat capacity, which will help to regulate the temperature rise due to accumulation of heat released from cement hydration in early-age mortar. In this section, we first analyze the thermal performance and stability of the PCM incorporated into the LWS, and then demonstrate the temperature regulation function of the LWS-PCM using semi-adiabatic calorimetry.

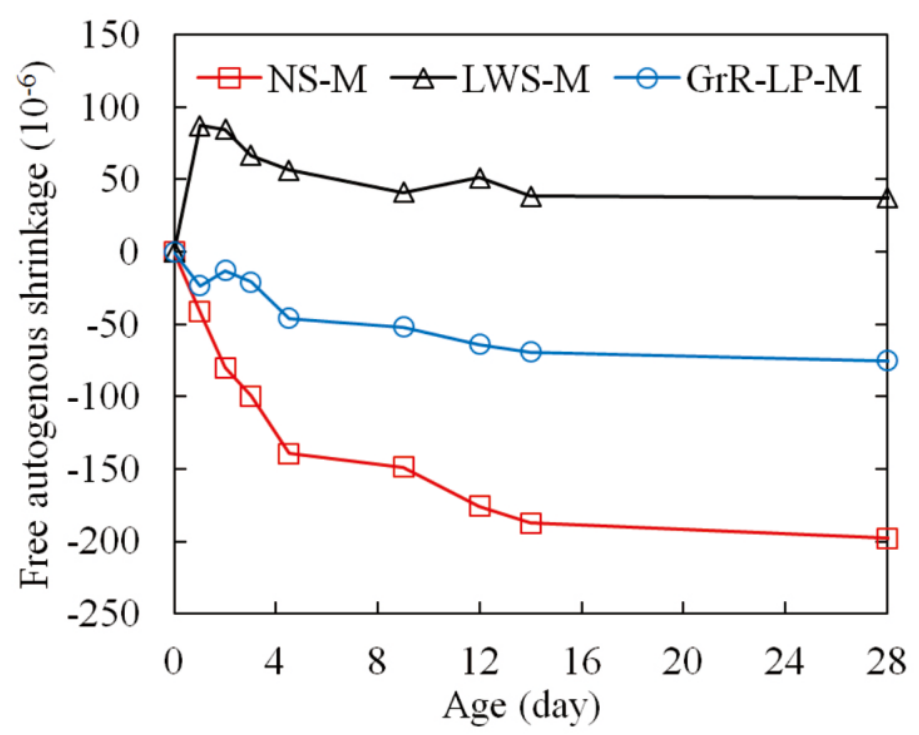

Fig. 13 Autogenous shrinkage evolutions of NS-M, LWS-M, and GrR-LP-M. 
Fig. 14 summarizes the thermal performance of the PCM. It can be seen that the PCM has a melting (crystallization) enthalpy of 232.8 $\mathrm{J} / \mathrm{g}(238.9 \mathrm{~J} / \mathrm{g})$ and the corresponding peak phase-transition temperatures of $29.3{ }^{\circ} \mathrm{C}\left(27.1{ }^{\circ} \mathrm{C}\right)$. The supercooling phenomenon rooted in the nucleation difficulty during cooling is responsible for the small difference between melting and crystallizing processes. ${ }^{47}$, 48 Additionally, the PCM is thermally stable without risk of decomposition when the temperature is below $110{ }^{\circ} \mathrm{C}$ in accordance with Fig. 14(b). Given that the temperature in early-age concrete is rarely higher than $80{ }^{\circ} \mathrm{C}$, even in mass concrete, the PCM is considered to be a reliable temperature regulator for the purpose of hydration heat and temperature rise management.

As recorded in Fig. 8, there is 15.6 vol\% PCM loaded into GrRLP. It is also known that the proportion of GrR-LP in the mortar is 60 vol\%. Hence, the GrR-LP-M is capable to carry about $83.3 \mathrm{~kg} / \mathrm{m}^{3} \mathrm{PCM}$ (given that the density of the PCM is $890 \mathrm{~kg} / \mathrm{m}^{3}$ ), which enables the mortar to store an extra energy of $19400 \mathrm{~kJ} / \mathrm{m}^{3}$ due to phase transition of the PCM. Since the specific heats of the paste with $0.4 \mathrm{w} / \mathrm{c}\left(\varphi_{\text {paste }}\right)$ and dry LWS $\left(\varphi_{\text {LWS }}\right)$ are $1.28 \mathrm{~kJ} / \mathrm{kg} /{ }^{\circ} \mathrm{C}$ and $1.15 \mathrm{~kJ} / \mathrm{kg} /{ }^{\circ} \mathrm{C}$, respectively, the specific heat of the composite LWS-M is calculated proportionately as
$1.21 \mathrm{~kJ} / \mathrm{kg} /{ }^{\circ} \mathrm{C}^{49}$ Consequently, the PCM endows the GrR-LP-M an ability to manipulate the temperature rise by $9.2{ }^{\circ} \mathrm{C}$ theoretically, as calculated by dividing the total latent of the embedded PCM by the specific heat of LWS-M and its measured density of $1740 \mathrm{~kg} / \mathrm{m}^{3}$. To verify the calculated capacity, the temperature evolution curves of three mortars, NS-M, LWS-M, and GrR-LP-M, are measured under semiadiabatic circumstance using the semi-adiabatic calorimetry, and the results are compared in Fig. 15.

Fig. 15 shows that the temperature evolution curve of the LWS-M is very close to that of the NS-M. The small difference might be attributed to the water carried by the LWS. As compared to them, the GrR-LP-M manifests an effective reduction of peak temperature as well as a delayed appearance of the peak temperature. The $7{ }^{\circ} \mathrm{C}$ reduction of peak temperature observed in Fig. 15 is $24 \%$ lower than the theoretical value of $9.2{ }^{\circ} \mathrm{C}$, perhaps because of the system error in the hydration heat measurement and the simplifications adopted in the calculation. In the above theoretical calculation, the specific heat of the LWS-PCMMortar composite is calculated by a simple way of proportional add-up, which ignores the air content of the mortar. In the meantime, it is inevitable that some hydration heat during mixing and before the

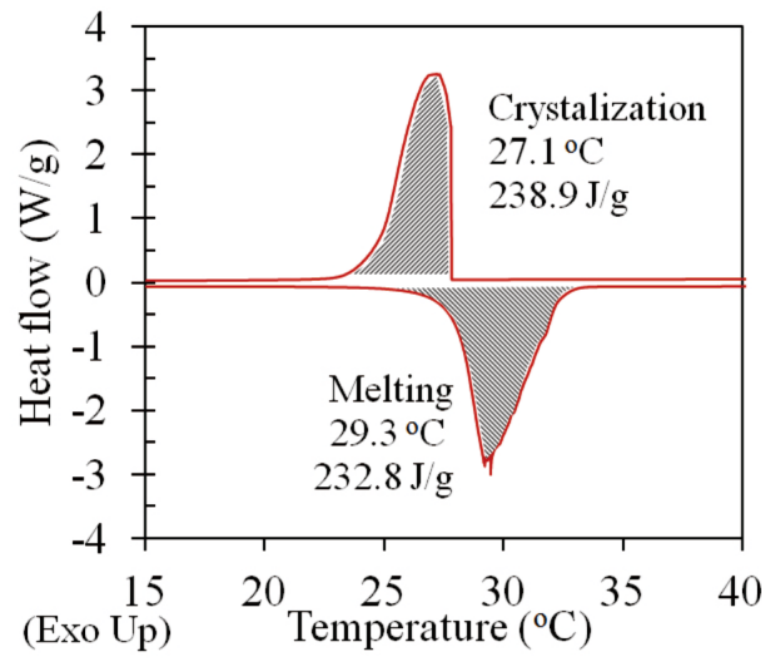

(a)

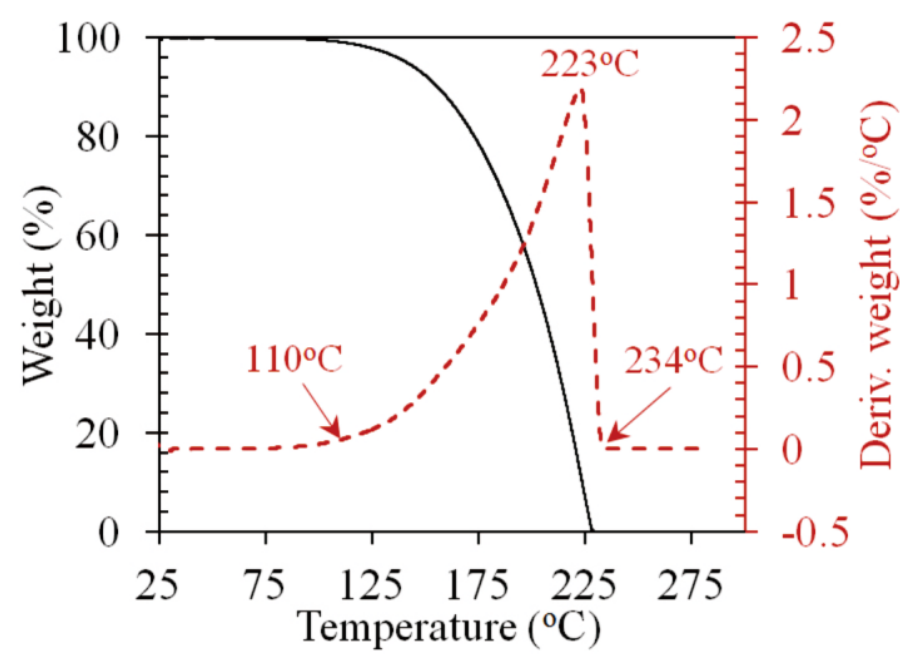

(b)

Fig. 14 Thermal performance of the PCM: (a) thermal capacity and phase transition temperatures determined by DSC test; (b) decomposition temperature of the PCM determined by a TGA test.

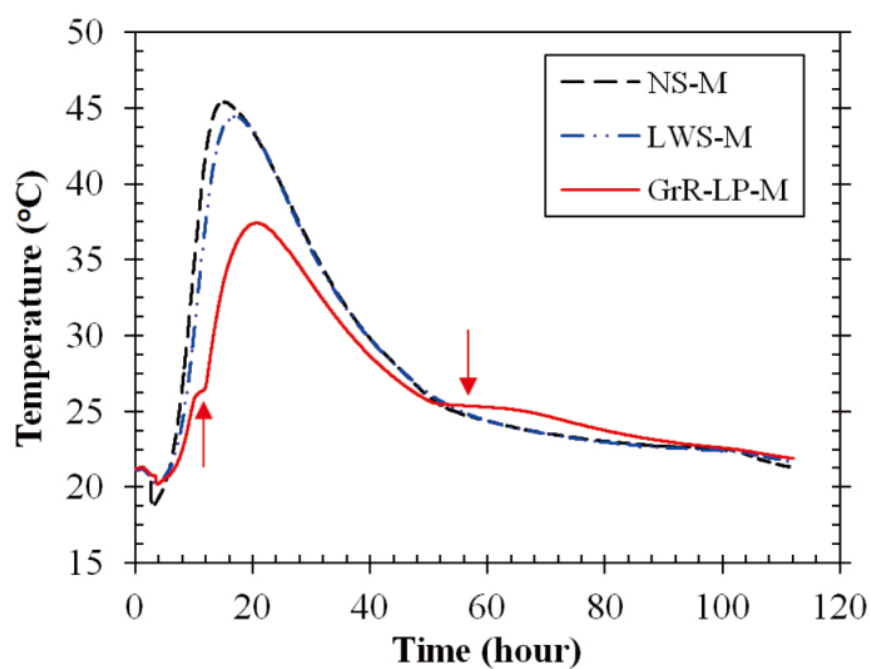

Fig. 15 Evaluation of temperature in three different mortars measured by semi-adiabatic calorimetry. 
measurement started was missed by the calorimeter. These errors leads to the difference between the calculated and measured values.

Moreover, two temperature buffering platforms in Fig. 15 are observed during increasing (heating) and decreasing (cooling) periods at around $26.3{ }^{\circ} \mathrm{C}$ and $25.4{ }^{\circ} \mathrm{C}$, respectively, which agrees with the characteristics of the embedded PCM. The small differences of phase transition temperatures between the GrR-LP-M and the PCM can be attributed to the pore confinement effect after PCM is loaded into the porous LWS. ${ }^{50}$ All in all, the GrR-LP-M has demonstrated a good capacity to control the temperature rise induced by the released hydration heat. The reduced peak temperature (meaning a smaller temperature gradient), delayed appearance of the peak temperature, as well as the gentled slope of the cooling curve all contribute to a reduced risk of thermal cracking in early-age concrete. ${ }^{51-53}$

This study has tested the feasibility of PCM to be used for thermal cracking control in early-age mass concrete. On-going study has been focusing on effects of the amount of PCM (or total latent heat capacity), phase transition temperature, and combination of multiple types of PCMs (with different phase transition temperatures) on the temperature management and thermal cracking control of early age concrete. The collected results will be presented in subsequent publications. Preliminary test has also shown that the hardened GrR-LP-M didn't show PCM leakage after 600 temperature cycles between $10{ }^{\circ} \mathrm{C}$ and $50{ }^{\circ} \mathrm{C}$, meaning that the cement paste penetrated into the surface pores of LWS can effectively control leakage. Theoretically, the stabilized PCM can significantly improve the adaptivity of aged mortar/concrete to temperature changes in the service environment. Such a function could be leveraged to mitigate the thermal curling and thermal fatigue induced cracking of rigid pavement. ${ }^{5,54}$ These possibilities will be elucidated in future studies. Last but not least, similar concepts of multifunctional aggregates can also be adopted in the research and development of emerging materials, such as alkali-activated cement, magnesium phosphate cement, and smart materials and systems. ${ }^{55-59}$

\section{Conclusions}

In this study, an innovative type of multifunctional lightweight aggregate is produced by loading PCM into the interior of LWS and sealing the surface pores of LWS using water (and subsequently cement hydration products when the saturated LWS is used as aggregate in mortar/concrete). The PCM and water loaded into the LWS functionalize it as not only a hydration heat or temperature rise management agent but also an internal curing agent. The following conclusions can be drawn from the present study:

(1) LWS particles have more irregular shapes and less smooth surfaces than natural sand, which result in better mechanical interlocking between cement paste matrix and the aggregate particles. When combined with internal curing that enhances the interfacial transition zones, the mortar proportioned with LWS can have comparable compressive strengths as compared to natural sand mortar, in spite of the use of weaker and softer LWS as aggregate.

(2) The LWS particles appear to have smaller surface pores and bigger internal pores, and the connected open pores take a volume fraction of $39.5 \%$ in the aggregate. These features of LWS render it as an ideal carrier to stabilize PCM. Under the optimized scenario, that is, GrR-LP in which PCM is only loaded into particles larger than 1.19 $\mathrm{mm}$ and the surface PCM residuum is rinsed off using warm water, the LWS can still carry $8.7 \mathrm{wt} \%$ or 15.6 vol\% PCM.

(3) The GrR-LP, prepared by grading, PCM impregnation, rinsing and water saturation, can effectively introduce PCM into mortar/concrete without compromising the compressive strength. Without the multi-step treatment, PCM residuum will remain, more or less, in the mortar. The residuum interrupts hydration of cement and affects the paste-aggregate interfacial bonding, leading to reduction of strength.

(4) The GrR-LP, when used as aggregate, can reduce the autogenous shrinkage of mortar by $63 \%$ because of the internal curing effect of partially saturated LWS.

(5) As demonstrated by semi-adiabatic calorimetry, the GrRLP, when used as aggregate in mass concrete, can reduce the peak temperature by $7{ }^{\circ} \mathrm{C}$, delay the appearance of the peak temperature, and gentle the cooling curve. All of these three aspects are positive to mitigate the risk of thermal cracking of early-age mass concrete.

In addition, the GrR-LP mortar did not show leakage after 600 thermal cycles, which proved that the developed processing method can effectively stabilize PCM in the aggregate and mortar/concrete. This gives potentially a bonus to the concrete, making it more adaptive to the temperature swings in the service environment.

\section{Acknowledgments}

Financial support from the seed funding program of the Advanced Materials for Sustainable Infrastructure (AMSI) signature area at Missouri University of Science and Technology (S\&T) is gratefully acknowledged. The technical support from the Materials Research Center at Missouri S\&T is also acknowledged.

\section{References}

1. A. Kasaeian, F. Pourfayaz, E. Khodabandeh and W. Yan, Energ. Buildings, 2017, 154, 96-112.

2. W. Yu, C. Liu, L. Qiu, P. Zhang, W. Ma, Y. Yue, H. Xie and L. Larkin, Eng. Sci., 2018, 2, 1-3.

3. J. da Cunha and P. Eames, Appl. Energ., 2016, 177, 227-238.

4. W. Choi, B. Khil, Y. Chae, Q. Liang and H. Yun, Sci. World J., 2014, 2014, 1-6.

5. N. Sharifi and K. Mahboub, Constr. Build. Mater, 2018, 183, 502-512.

6. Y. Farnam, M. Krafcik, L. Liston, T. Washington, K. Erk, B. Tao and J. Weiss, J. Mater. Civil Eng., 2015, 28, 04015161.

7. A. Eddhahak, S. Drissi, J. Colin, S. Caré and J. Neji, J. Therm. Anal. Calorim., 2014, 117, 537-545.

8. A. R. Sakulich and D.P. Bentz, Constr. Build. Mater, 2012, 35, 483-490.

9. D. P. Bentz, K. A. Snyder, L.C. Cass and M. A Peltz, Cem. Concr. Compos., 2008, 30, 674-678.

10. H. Cui, W. Liao, X. Mi, T. Lo and D. Chen, Energ. Buildings, 2015, 105, $273-$ 284.

11 B. Xu, H. Ma, Z. Lu and Z. Li, Appl. Energ., 2015, 160, 358-367.

12. H. Cui, W. Tang, Q. Qin, F. Xing, W. Liao and H. Wen, Appl. Energ., 2017, 185, 107-118.

13. Y. Milian, A. Gutierrez, M. Grageda and S. Ushak, Renew. Sust. Energ. Rev, 2017, 73, 983-999.

14. S. Drissi, T. Ling, K. Mo and A. Eddhahak, Renew. Sust. Energ. Rev., 2019, $110,467-484$.

15. M. Li, Z. Wu and J. Tan, Appl. Energ., 2013, 103, 393-399.

16. H. Cui, W. Liao, S. Memon, B. Dong and W. Tang, Materials, 2014, 7, 80708087.

17. T. Ling and C. Poon, Constr. Build. Mater, 2013, 46, 55-62.

18. S. Pilehvar, V. Cao, A. Szczotok, L. Valentini, D. Salvioni, M. Magistri, R. Pamies and A. Kjøniksen, Cem. Concr. Res., 2017, 100, 341-349.

19. S. Ramakrishnan, X. Wang, J. Sanjayan and J. Wilson, Procedia Eng., 2017, 180, 1170-1177. 
20. T. Nochaiya, T. Jeenram, P. Disuea and P. Torkittikul, Monatsh. Chem., 2017, 148, 1363-1370.

21. E. Mohseni, W. Tang and S. Wang, Molecules, 2019, 24, 1360.

22. H. Cui, T. Feng, H. Yang, X. Bao, W. Tang, and J. Fu, Constr. Build. Mater, 2018, 161, 442-451.

23. M. Aguayo, S. Das, C. Castro, N. Kabay, G. Sant and N. Neithalath, Constr. Build. Mater, 2017, 134, 574-584.

24. S. Das, M. Aguayo, N. Kabay, B. Mobasher, G. Sant and N. Neithalath, Cem. Concr. Compos., 2018, 94, 13-23.

25. J. Liu, C. Shi, X. Ma, K. Khayat, J. Zhang and D. Wang, Constr. Build. Mater, 2017, 146, 702-712.

26. D. Bentz and R. Turpin, Cem. Concr. Compos.., 2007, 29, 527-532.

27. Y. Farnam, H. Esmaeeli, P. Zavattieri, J. Haddock and J. Weiss, Cem. Concr. Compos., 2017, 84, 134-145.

28. S. Afgan, Doctoral dissertation, NUST, 2017.

29. S. Memon, H. Cui, H. Zhang and F. Xing, Appl. Energ., 2015, 139, 43-55. 30. W. Meng and K. Khayat, Cem. Concr. Res., 2017, 101, 46-54.

31. W. Meng and K. Khayat, Compos. Part B-Eng., 2017, 117, 26-34.

32. A. Miller, T. Barrett, A. Zander and W. Weiss, Advances in Civil Engineering Materials, 2014, 3, 142-157.

33. F. Dazzo, D. Trione, E. Mashall and J. Zurdo, "CMEIAS Ver. 1.28 User Manual," http://cme.msu.edu/cmeias/cmeias128/Cmeias128.pdf. [Accessed 2 Sep. 2019].

34. H. Ma, J. Porous Mater, 2014, 21, 207-215.

35. H. Ma and Z. Li, Comput. Concr., 2013, 11, 317-336.

36. D. Kuang, B. Zhang, Y. Jiao, J. Fang, H. Chen and L. Wang, Constr. Build. Mater, 2017, 132, 142-149.

37. M. A. Wirth, "Shape analysis \& measurement,"

http://www.cyto.purdue.edu/cdroms/micro2/content/education/wirth10.pdf. [Accessed 2 Sep. 2019].

38. N. Morrow, Ind. Eng.,1970, 62, 32-56.

39. T. Kato, K. Ohashi, M. Fuji and M. Takahashi, J. Ceram. Soc. Jpn., 2008, 116, 212-215.
40. J. Vanson, A. Boutin, M. Klotz and F. Coudert, Soft Matter, 2017, 13, 8758857.

41. R. Henkensiefken, D. Bentz, T. Nantung and J. Weiss, Cem. Concr. Compos., 2009, 31, 427-437.

42. S. Kang, S. Hong and J. Moon, Cem. Concr. Compos., 2018, 89, 130-138. 43. D. Snoeck, O. Jensen and N. De Belie, Cem. Concr. Res., 2015, 74, 59-67.

44. C. Schröfl, V. Mechtcherine and M. Gorges, Cem. Concr. Res., 2012, 42, 865 873.

45. A. Bentur, S. Igarashi and K. Kovler, Cem. Concr. Res., 2001, 31, 1587-1591. 46. L. Barcelo, M. Moranville and B. Clavaud, Cem. Concr. Res., 2005, 35, $177-183$.

47. M. Avrami, J. Chem. Phys., 1939, 7, 1103-1112.

48. A. Safari, R. Saidur, F. Sulaiman, Y. Xu and J. Dong, Renew. Sust. Energ. Rev, 2017, 70, 905-919.

49. S. Yoon, D. Macphee and M. Imbabi, Thermochim. Acta, 2014, 588, 1-10.

50. E. Santiso, A. George, K. Gubbins and M. Nardelli, J. Chem. Phys., 2006, 125, 084711.

51. A. Neville, Properties of concrete (5th Edition), London: Pearson, 2011.

52. Y. Kim, B. Khil, S. Jang, W. Choi and H. Yun, Thermochim. Acta, 2015, 613, 100-107.

53. Z. Wei, G. Falzone, S. Das, N. Saklani, Y. Le Pape, L. Pilon, N. Neithalath and G. Sant, Mater. Des., 2017, 132, 367-374.

54. A. Arora, G. Sant and N. Neithalath, Cem. Concr. Compos., 2017, 81, 11-24. 55.T. Zhuo, W. Li, Y. Hu, J. L. Zhou and V. W.Y. Tam, Constr. Build. Mater. 2019, 200, 474-489.

56. H. Ma and B. Xu, Mater. Des., 2017, 118, 81-88.

57. W. Dong, W. Li, N. Lu, F. Qu, K. Vessalas and D. Sheng, Compos. Part BEng., 2019, 178, 107488.

58. W. Dong, W. Li, K. Wang, Z. Luo and D. Sheng, Sens. Actuators A Phys., 2020, 301, 111763.

59. W. Dong, W. Li, L. Shen and D. Sheng, Mater. Des., 2019, 182, 108012.

Publisher's Note Engineered Science Publisher remains neutral with regard to jurisdictional claims in published maps and institutional affiliations. 